\title{
POTENCIAL DE RENDIMENTO DE GRÃOS DE MILHO EM DOIS AMBIENTES E CINCO SISTEMAS DE PRODUÇÃO
}

\author{
MAIZE GRAIN YIELD POTENTIAL AT TWO ENVIRONMENTS AND FIVE \\ PRODUCTION SYSTEMS
}

\author{
Gilber ARGENTA ${ }^{1}$ \\ Luís SANGOI ${ }^{2}$ \\ Paulo Regis Ferreira da SILVA ${ }^{3}$ \\ Clair RAMPAZZO ${ }^{4}$ \\ Luís Carlos GRACIETTI ${ }^{4}$ \\ Mércio Luiz STRIEDER ${ }^{5}$ \\ Everton Leonardo Forsthofer ${ }^{5}$ \\ Elias SUHRE 5
}

\begin{abstract}
RESUMO
A determinação do potencial de rendimento do milho em ambientes contrastantes é importante para identificar fatores limitantes ao incremento da produção. Este trabalho foi conduzido objetivando determinar o efeito do ambiente sobre o potencial de rendimento do milho, em diferentes sistemas de produção. Foram conduzidos dois experimentos: o primeiro em Eldorado do Sul, RS ( $30^{\circ} 05^{\prime} \mathrm{S}, 46$ metros de altitude); o segundo em Lages, SC (2752' S, 930 metros de altitude). Em cada local avaliou-se cinco sistemas de produção (S), equivalentes a diferentes níveis tecnológicos e expectativas de rendimento. S1, S2 e S3 representaram baixo, médio e alto nível de manejo, respectivamente. S4 e S5 foram sistemas propostos objetivando potencializar o rendimento de grãos. Os rendimentos variaram de 3,0 a 15,0 t.ha ${ }^{-1} \mathrm{em}$ Eldorado do Sul e de 3,2 a 15,9 t.ha-1 em Lages. Não houve diferenças entre ambientes no rendimento de grãos obtido em $\mathrm{S} 1$ e S2. Os rendimentos registrados em Lages foram 0,9 t.ha-1 maiores do que em Eldorado do Sul em S4 e S5. O efeito do ambiente sobre a performance agronômica do milho é mais importante quando são utilizadas práticas de manejo que possibilitem altos tetos de rendimento. Nestas condições, Lages apresenta maior potencial para obtenção de produtividades elevadas do que Eldorado do Sul, devido a maior relação entre radiação disponível por unidade térmica de desenvolvimento no início do enchimento de grãos.
\end{abstract}

Palavras-chave: Zea mays, potencial produtivo, sistema produtivo.

\begin{abstract}
The determination of maize yield potential under different environmental conditions is important to identify limiting factors to improve crop productivity. This experiment was conducted aiming to determine the effects of the environment on maize grain yield at five production systems. The trials were conducted in Eldorado do Sul ( $30^{\circ} 05^{\prime} \mathrm{S}, 46$ meters above sea level) and Lages (27 $52^{\prime} \mathrm{S}, 930$ meters above sea level). Both experimental sites were located in Southern Brazil. Five cropping systems (S) were tested at each place. S1, S2 and S3 corresponded to low, medium and high input management systems, respectively. S4 and S5 were systems established to maximize maize productivity. Grain yield ranged from 3.0 to 15.0 tha $^{-1}$ in Eldorado do Sul and 3.2 to 15.9 tha $^{-1}$ in Lages. No difference in grain yield between experimental sites was observed for S1 and S2. Conversely, maize productivity was 0.9 ton ha ${ }^{-1}$ higher in Lages than in Eldorado do Sul for S4 and S5. The environment effect on maize agronomic performance is more important when growers use management practices that allow them to accomplish high grain yield. Under these conditions, Lages presents greater potential to reach high yield plateau than Eldorado do Sul, due to its larger relation between the available radiation per thermal unit during maize early grain filling.

Key-words: Zea mays, potential production, production system.
\end{abstract}

\footnotetext{
${ }^{1}$ Engenheiro Agrônomo, Dr. Pesquisador da FEPAGRO. Gonçalves Dias, 570, CEP 90.130-060, Porto Alegre, RS. Bolsista Recém-Doutor da FAPERGS. E-mail: argentag@cpovo.net *Autor para correspondência;

${ }^{2}$ Engenheiro Agrônomo, Ph.D. Professor Adjunto da Faculdade de Agronomia da CAV/UDESC. Av. Luiz de Camões, 2090, CEP 88.520-000, Lages, SC. Bolsista do CNPq. E-mail: a2ls@cav.udesc.br;

${ }^{3}$ Engenheiro Agrônomo, Ph.D. Professor Adjunto da Faculdade de Agronomia da UFRGS. Bolsista do CNPq. E-mail: paulo.silva@vortex.ufrgs.br; ${ }^{4}$ Estudante da Faculdade de Agronomia da CAV/UDESC. Bolsista de iniciação científica do CNPq;

${ }^{5}$ Estudante da Faculdade de Agronomia da UFRGS. Bolsista de iniciação científica do CNPq.
} 


\section{INTRODUÇÃO}

O potencial de rendimento das culturas pode ser definido como o rendimento apresentado pelas mesmas quando cultivadas em ambiente ao qual estão adaptadas, sem limitações no suprimento de água e nutrientes, com o controle efetivo de insetos, doenças, plantas daninhas, excessos hídricos e de outros estresses bióticos e abióticos (7).

O milho é uma das espécies de importância agrícola que apresenta maior potencial de utilização da radiação solar para a conversão de carbono mineral em carbono orgânico e o seu posterior acúmulo nos grãos (22). O seu potencial de rendimento grãos em cada ambiente depende principalmente de quatro fatores: da quantidade de radiação incidente, da eficiência de interceptação da radiação incidente, da eficiência de conversão da radiação interceptada em biomassa vegetal e da eficiência de partição de assimilados à estrutura de interesse econômico (2). Alcançar elevados tetos produtivos com esta cultura é uma tarefa teoricamente simples. Para viabilizá-la há necessidade de maximizar a duração do período de interceptação da radiação incidente; otimizar a eficiência de uso da radiação interceptada na fotossíntese; distribuir os fotoassimilados produzidos adequadamente, de forma a propiciar crescimento equilibrado de raízes, folhas, colmos e estruturas reprodutivas; e minimizar os custos respiratórios para manutenção do desenvolvimento vegetativo e reprodutivo (14). Contudo, a multiplicidade dos fatores que interferem sobre a capacidade assimilatória da planta e a eficiência metabólica dos diferentes processos que atuam sobre o rendimento de grãos aumentam a complexidade da tarefa de maximizar a sua produtividade (8).

A quantidade de radiação incidente disponível é um fator que depende principalmente da posição geográfica de cada região produtora, de sua latitude, longitude e altitude (13). Além destes, a época de semeadura da cultura exerce papel preponderante sobre esta variável. Já a eficiência de interceptação da radiação e de sua conversão e partição em produtos orgânicos estará na dependência de fatores climáticos, com destaque para temperatura e disponibilidade hídrica; edáficos, com ênfase à fertilidade, estrutura e textura de solo; e de manejo, destacando-se práticas culturais que interfiram sobre a densidade populacional e o arranjo de plantas $(3,19)$.

A investigação dos limites da produtividade contribuirá para identificar as variáveis do ambiente responsáveis pelo desempenho final da cultura e ressaltar em que nível cada uma delas representa estrangulamento à expressão máxima da produtividade (4). Neste sentido, a determinação do potencial de rendimento de grãos de milho em ambientes diferentes torna-se ferramenta importante para a tomada de decisões no manejo e também no melhoramento desta cultura, por possibilitar a identificação dos fatores limitantes. Dimensionando-se o impacto dos fatores restritivos ao rendimento, poder-se-á definir estratégias de como superá-los ou minimizá-los através do manejo adequado das condições ambientais ou mediante seleção e melhoramento genético. A combinação desses dois fatores permitirá maximizar a exploração dos recursos de cada ambiente de produção, buscando otimizar a produtividade das espécies de importância agrícola de uma forma sustentável (21).

Este trabalho foi conduzido com o objetivo de avaliar o efeito do ambiente sobre o potencial de rendimento de grãos de milho cultivado em diferentes sistemas de produção.

\section{METODOLOGIA}

Dois experimentos foram conduzidos no ano agrícola 2000/2001. O primeiro foi implantado em 16/ 10/00, no município de Eldorado do Sul, região fisiográfica da Depressão Central do estado do Rio Grande do Sul, localizado a 3005'52" de latitude sul, numa altitude de 46 metros acima do nível do mar. 0 clima da região é classificado por Köppen como subtropical úmido, situado na transição entre os tipos fundamentais $\mathrm{cfa}_{1}$ (isoterma anual inferior a $18^{\circ} \mathrm{C}$ ) e $\mathrm{cfa}_{2}$ (isoterma anual superior a $18^{\circ}$ ). O solo da área experimental pertence à unidade de mapeamento São Jerônimo, sendo classificado como Argiloso VermeIho Distrófico Típico (6).

O segundo experimento foi implantado em 20/ 10/00, no município de Lages, região fisiográfica do Planalto Sul do Estado de Santa Catarina, localizado a $27^{\circ} 52^{\prime} 30^{\prime \prime}$ de latitude sul e 930 metros acima do nível do mar. O clima da região é do tipo Cfb, mesotérmico, com verões brandos, temperaturas médias do mês mais quente inferiores a $22^{\circ} \mathrm{C}$ e precipitações pluviais bem distribuídas. O solo da área experimental é classificado como Nitossolo VermeIho Distrófico Típico (6).

Em cada local, testou-se cinco sistemas de produção, equivalentes a diferentes níveis de manejo e expectativas de rendimento de grãos. Os sistemas 1 , 2 e 3 foram fundamentados nas recomendações técnicas vigentes para a cultura do milho no estado do Rio Grande do Sul (16), representando, respectivamente, baixo, médio e alto nível de manejo. Os sistemas 4 e 5 foram propostos objetivando potencializar o rendimento de grãos de milho em cada ambiente.

Utilizou-se as variedades de polinização aberta CEP 304 e Amarelão do Campo Belo no sistema 1 em Eldorado do Sul e Lages, respectivamente. No sistema 2 , a cultivar de milho reagente utilizada nos dois ambientes foi o híbrido duplo de ciclo precoce Agroceres 303. Nos sistemas de manejo do milho de 3 a 5 foi utilizada nos dois ambientes a cultivar Pioneer 32R21, híbrido simples e de ciclo superprecoce.

A adubação nitrogenada utilizada nos sistemas 1 a 3 , foi baseada nas expectativas de rendimento de $<3$, 3-6 e $>9 \mathrm{t} / \mathrm{ha}$, respectivamente, para os sistemas 1, 2 e 3. Nos sistemas 4 e 5, a adubação nitrogenada utilizada foi o dobro da utilizada no sistema 3. A adubação fosfatada e potássica utilizada nos sistemas 1 a 3 foi baseada nas recomendações técnicas para a cultu- 
ra do milho no RS (16). A dose utilizada de $\mathrm{P}$ e $\mathrm{K}$ foi baseada no valor de reposição dentro da expectativa de rendimento de $<3,3-6$ e $>6$ t/ha, respectivamente, para os sistemas 1, 2 e 3. Nos sistemas 4 e 5, a adubação utilizada foi o dobro da utilizada no sistema 3. Nestes dois últimos sistemas, também foram aplicados os micronutrientes óxido de zinco, molibdênio e boro, nas doses de 125,5 e $1 \mathrm{~g} \cdot 100^{-1} \mathrm{~kg}$ de sementes por ocasião do tratamento de sementes.

A densidade de plantas utilizada nos sistemas 1 a 3 foi baseada no nível de manejo e na expectativa de rendimento de grãos. A dos demais sistemas em função de resultados de outros experimentos (3). O espaçamento entre linhas utilizado nos sistemas 1 a 3 foi baseado nas recomendações técnicas para a cultura do milho (16). A dos demais sistemas em função de resultados de outros experimentos (3). Os valores numéricos referentes as principais características de cada sistema podem ser visualizadas na Tabela 1 .

TABELA1 - Principais características de manejo de cinco sistemas de produção de milho em dois ambientes contrastantes, 2000/2001.

\begin{tabular}{|c|c|c|c|c|c|c|}
\hline \multirow{3}{*}{$\begin{array}{c}\text { Sistemas de } \\
\text { Manejo } \\
\text { do milho }\end{array}$} & \multicolumn{4}{|c|}{ Adubação (kg.ha-1) } & \multirow{3}{*}{$\begin{array}{c}\text { Densidade } \\
\text { De } \\
\text { Plantas } \\
\text { (planta.ha }^{-1} \text { ) }\end{array}$} & \multirow{3}{*}{$\begin{array}{c}\text { Espaçamento } \\
\text { Entre } \\
\text { Linhas }(\mathrm{cm})\end{array}$} \\
\hline & \multicolumn{2}{|c|}{$\mathrm{N}$} & \multirow{2}{*}{$\mathrm{P}$} & \multirow{2}{*}{ K } & & \\
\hline & $\begin{array}{l}\text { Eldorado do } \\
\text { Sul-RS }\end{array}$ & Lages-SC & & & & \\
\hline $\begin{array}{l}\text { S1 - Baixo nível de } \\
\text { manejo }\end{array}$ & 40 & 40 & 25 & 30 & 35.000 & 80 \\
\hline $\begin{array}{l}\text { S2 - Médio nível de } \\
\text { manejo }\end{array}$ & 80 & 70 & 40 & 60 & 50.000 & 80 \\
\hline $\begin{array}{l}\text { S3 - Alto nível de } \\
\text { manejo }\end{array}$ & 160 & 80 & 70 & 100 & 70.000 & 80 \\
\hline S4 - Potencial I & 320 & 160 & 140 & $\begin{array}{c}200 \\
+ \text { micro- } \\
\text { nutrientes }\end{array}$ & 80.000 & 40 \\
\hline S5 - Potencial II & 320 & 160 & 140 & $\begin{array}{c}200 \\
\text { +micro- } \\
\text { nutrientes }\end{array}$ & 100.000 & 40 \\
\hline
\end{tabular}

Os ensaios foram implantados no sistema de semeadura direta, em sucessão ao consórcio de ervilhaca comum e aveia preta em Eldorado do Sul e de aveia preta em Lages. Toda a adubação fosfatada e potássica foi aplicada nos sulcos de semeadura, no dia da implantação de cada ensaio, excetuandose S4 e S5 em Eldorado do Sul. Nestes sistemas, aplicou-se metade da adubação potássica na base e metade em cobertura quando o milho apresentava seis a sete folhas expandidas. Aplicou-se $30 \mathrm{~kg}$ de $\mathrm{N}$ na semeadura em todos os sistemas. Nos sistemas S4 e S5 aplicou-se 125, 5 e $1 \mathrm{~g}$ de óxido de zinco, molibdênio e boro, respectivamente, mais $300 \mathrm{~g}$ de i.a. do inseticida tiodicarb, para cada $100 \mathrm{~kg}$ de sementes, tratando-as no dia da semeadura.

A época de realização da cobertura nitrogenada variou de acordo com o sistema de manejo. Para os sistemas 1 e 2, efetuou-se uma aplicação em cobertura no estádio de seis a sete folhas expandidas. No Sistema 3 a cobertura nitrogenada foi parcelada em duas vezes: três a quatro e sete a oito folhas expandidas. Para S4 e S5 o parcelamento do $\mathrm{N}$ em cobertura foi feito em três épocas: três a quatro, seis a sete e 10 a 11 folhas expandidas. Efetuou-se uma aplicação de micronutrientes via foliar em S4 e S5, aspergindo-se uma solução com $0,2 \%$ de sulfato de zinco quando o milho apresentava oito folhas expandidas.

Nos sistemas 3, 4 e 5 a quantidade de água disponível no solo foi sempre mantida próxima da capacidade de campo mediante suplementação hídrica. A necessidade de irrigação foi estimada pela instalação de seis tensiômetros na área experimental, sendo três na profundidade de $25 \mathrm{~cm}$ e três na de $50 \mathrm{~cm}$. A irrigação foi realizada quando o potencial de água no solo foi inferior a $-0.04 \mathrm{Mpa}$.

As parcelas foram constituídas por sete a 12 linhas de seis metros de comprimento, dependendo do local e sistema de produção. As determinações foram efetuadas numa área útil de $12 \mathrm{~m}^{2} \mathrm{em}$ todas as parcelas. O delineamento experimental utilizado foi o de blocos casualizados, com quatro repetições por tratamento.

Em cada local experimental determinou-se o rendimento de grãos, os componentes do rendimento, a produção de fitomassa total da planta (rendimento biológico) e a eficiência da planta em alocar matéria seca à estrutura de interesse econômico (índice de colheita).

Os dados meteorológicos referentes à precipitação pluvial, temperaturas máxima e mínima do ar e radiação solar foram obtidos nas unidades meteorológicas da Estação Experimental Agronômica da Universidade Federal do Rio Grande do Sul, em Eldorado do Sul, e da Empresa Catarinense de Pesquisa Agropecuária e Extensão Rural, em Lages. Estes dados foram utilizados para o cálculo do balanço hídrico, conforme metodologia desenvolvida por Thornthwaite e Matter, apresentada por Ometto (15). 
Os dados obtidos foram submetidos à análise de variância, considerando-se o ambiente como fator aleatório. Quando alcançada significância estatística, as médias foram comparadas pelo teste de Duncan, a $5 \%$ de probabilidade.
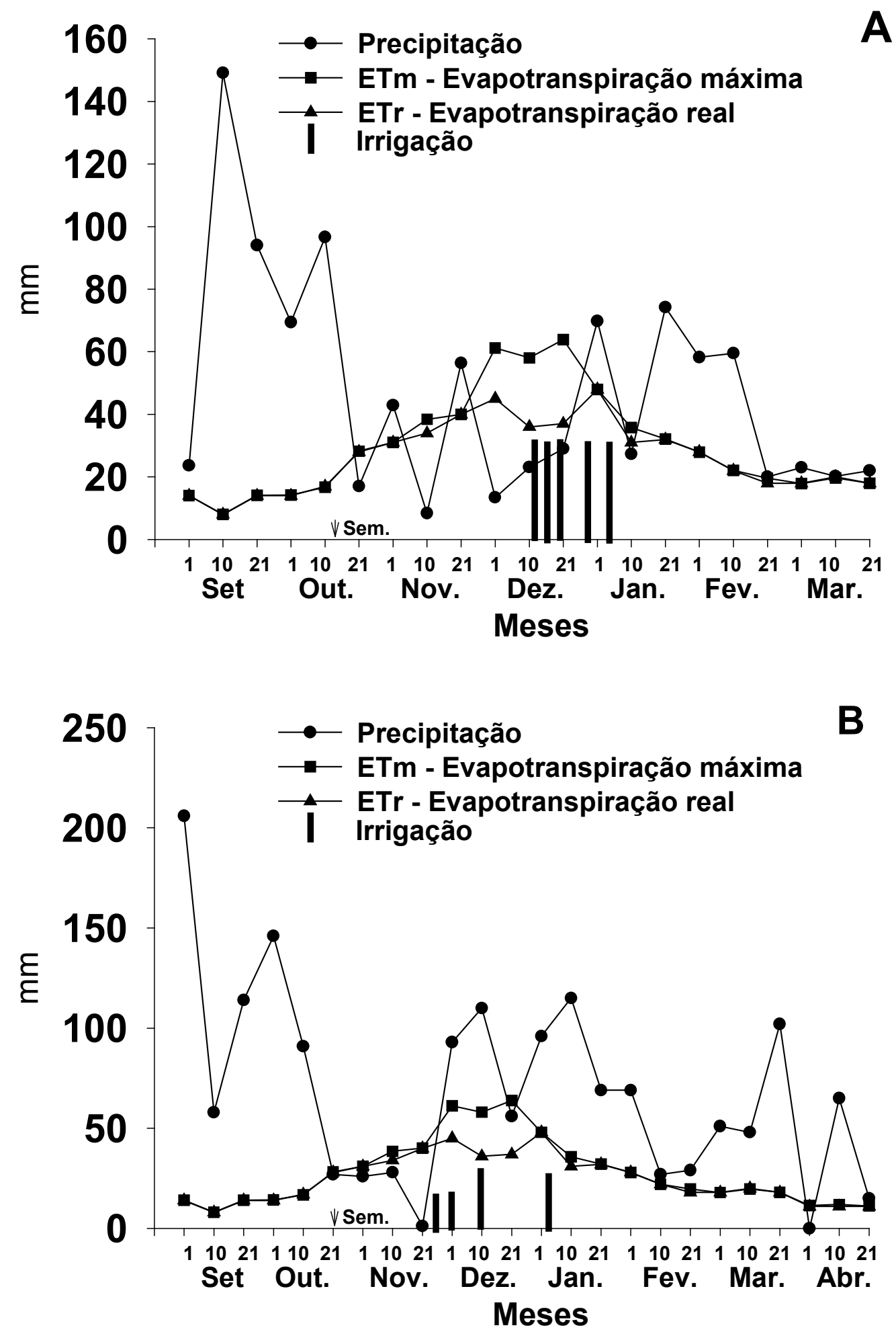

FIGURA 1 - Balanço hídrico segundo Thorntwaite e Mather, apresentada por Ometto (15) modificado para capacidade de armazenamento de água no solo de 75mm em Eldorado do Sul-RS (A) e Lages-SC (B), 2000/2001. 
TABELA 2 - Rendimento de grãos, índice de colheita, número de grãos por espiga e peso de mil grãos de milho sob cinco sistemas de manejo, em dois ambientes contrastantes. 2000/01.

\begin{tabular}{|c|c|c|c|c|c|}
\hline \multirow[t]{2}{*}{ Locais } & \multicolumn{5}{|c|}{ Sistemas de manejo do milho } \\
\hline & S1 & S2 & S3 & S4 & S5 \\
\hline & \multicolumn{5}{|c|}{ Rendimento de grãos (t.ha) } \\
\hline $\begin{array}{l}\text { Eldorado do } \\
\text { Sul - RS }\end{array}$ & D $3,0 a^{1}$ & C 4,9 a & B 11,9 a & A 14,2 b & A $15,0 \mathrm{~b}$ \\
\hline Lages - SC & D 3,2 a & C 5,4 a & B $9,9 \mathrm{~b}$ & A 15,1 a & A 15,9 a \\
\hline \multicolumn{6}{|l|}{ C.V. $(\%)=5,6$} \\
\hline $\begin{array}{l}\text { Eldorado do } \\
\text { Sul - RS }\end{array}$ & B 0,25 b & A 0,50 a & $\begin{array}{c}\text { ice de coll } \\
\text { A } 0,50 \text { a }\end{array}$ & A $0,50 \mathrm{~b}$ & A $0,50 \mathrm{~b}$ \\
\hline Lages - SC & $\mathrm{D} 0,36 \mathrm{a}$ & $\mathrm{C} 0,39 \mathrm{~b}$ & B 0,50 a & A 0,53 a & A 0,54 a \\
\hline \multicolumn{6}{|l|}{ C.V. $(\%)=5,8$} \\
\hline & \multicolumn{5}{|c|}{ Grãos/espiga $\left(n^{\circ}\right)$} \\
\hline $\begin{array}{l}\text { Eldorado do } \\
\text { Sul - RS }\end{array}$ & E 234 b & D 339 a & A 529 a & B 487 b & C $420 \mathrm{~b}$ \\
\hline Lages - SC & D $275 a$ & C 367 a & B $460 \mathrm{~b}$ & A 525 a & AB 484 a \\
\hline \multicolumn{6}{|l|}{ C.V. $(\%)=5,9$} \\
\hline & \multicolumn{5}{|c|}{ Peso de mil grãos (g) } \\
\hline $\begin{array}{c}\text { Eldorado do } \\
\text { Sul - RS }\end{array}$ & B 352 a & C 317 a & B 353 a & A 370 a & AB 359 a \\
\hline Lages - SC & B 333 b & D $289 \mathrm{~b}$ & C $304 \mathrm{~b}$ & A 358 a & AB 349 a \\
\hline C.V. $(\%)=2,8$ & & & & & \\
\hline
\end{tabular}

${ }^{1}$ Médias antecedidas pela mesma letra maiúscula na linha e seguidas pela mesma letra minúscula na coluna não diferem entre si significativamente pelo teste de Duncan, ao nível de $5 \%$ de probabilidade.

\section{RESULTADOS E DISCUSSÃO}

O balanço hídrico do ano agrícola 2000/2001 mostra que não houve períodos prolongados de restrição hídrica que pudessem comprometer a performance da cultura, tanto em Eldorado do Sul quanto em Lages (Figura 1). O número de irrigações complementares efetuadas para S3, S4, S5 foi pequeno e esteve concentrado principalmente no mês de dezembro. Por outro lado, a precipitação foi sempre superior a evapotranspiração potencial da cultura nos meses de janeiro e fevereiro, que compreenderam o período de florescimento (para as cultivares usadas em S1 e S2) e enchimento de grãos da cultura. Isto indica que a disponibilidade hídrica na fase reprodutiva do ciclo da cultura foi adequada à obtenção de rendimentos satisfatórios, mesmo nos sistemas em que não se utilizou suplementação hídrica.

Os rendimentos variaram de 3,0 a 15,0 t.ha $^{-1}$ em Eldorado do Sul e de 3,2 a 15,9 t.ha-1 em Lages, dependendo do sistema de produção adotado, sendo tanto mais altos quanto maior o investimento em manejo, nos dois ambientes avaliados (Tabela 2). $\mathrm{Na}$ média dos dois ambientes testados, o rendimento de grãos obtido nos sistemas destinados a potencializar a produtividade da cultura foi $28 \%$ (70 sacos/ha), $66 \%$ (166 sacos/ha) e 79\% (200 sacos/ha) superior aos rendimentos obtidos em S3, S2 e S1, respectivamen- te. O número de espigas produzidas por planta não foi afetado significativamente pelo sistema de manejo adotado e ambiente, oscilando entre 0,95 e 1,04 , dependendo do tratamento avaliado (dados não mostrados). Assim, a melhor performance técnica alcançada nos sistemas com maior investimento em manejo deveu-se, principalmente, ao maior número de espigas colhidas por área, decorrente da maior densidade de plantas, e a maior produção de grãos por $\mathrm{m}^{2}$. Isto confirmou as observações feitas alguns pesquisadores $(9,12,23)$ de que o número de grãos produzidos por unidade de área é o componente do rendimento mais importante para a obtenção de altos tetos de rendimento com a cultura do milho.

Não se observaram diferenças significativas entre ambientes no rendimento de grãos obtido nos sistemas de produção definidos como de baixo e médio nível de investimento em manejo. Nestes casos, as produtividades alcançadas foram compatíveis com as metas propostas previamente em cada pacote tecnológico (16), ficando em torno de 3,1 t.ha-1 para o Sistema 1 e 5,2 t.ha-1 no Sistema 2, na média dos dois locais.

O rendimento de grãos obtido em S3 foi significativamente maior em Eldorado do Sul do que em Lages (Tabela 2). Isto provavelmente ocorreu porque a quantidade de nitrogênio utilizada neste sistema no Planalto Catarinense ( $\left.80 \mathrm{~kg} \mathrm{ha}^{-1}\right)$ foi insuficiente para sustentar tetos de produtividade superiores a 10 t.ha $^{-1}$, mes- 
mo num solo com alto teor de matéria orgânica. São necessários aproximadamente $20 \mathrm{~kg}$ de $\mathrm{N}$ para cada tonelada de grãos de milho produzida (20). Desta forma, a mineralização da matéria orgânica e a quantidade de $\mathrm{N}$ mineral aplicada provavelmente não foram suficientes para suprir mais do que $200 \mathrm{~kg}$ de $\mathrm{N}$ $\mathrm{ha}^{-1}$ à cultura em Lages. Isso provavelmente limitou a atividade fotossintética da planta, apressou a senescência foliar e restringiu o rendimento de grãos, em relação ao Eldorado do Sul, onde a dose de $\mathrm{N}$ utilizada em S3 foi de $160 \mathrm{~kg} \mathrm{ha}^{-1}$ (Tabelas 1 e 2).

Por outro lado, nos sistemas em que se objetivou otimizar a performance agronômica da cultura, verificou-se rendimentos de grãos significativamente maiores em Lages do que em Eldorado do Sul (Tabela 2). O adicional de produtividade obtido no Planalto Catarinense foi de $0,9 \mathrm{t} \mathrm{ha}^{-1}$, tanto em S4 quanto em S5. As maiores produtividades registradas em Lages nestes sistemas deveram-se a maior número de grãos produzidos por espiga (Tabela 2). Observou-se também maior eficiência da planta em alocar matéria seca para a estrutura de interesse econômico (índice de colheita) no Planalto Catarinense do que na Depressão Central, nos sistemas destinados a maximizar a produtividade da cultura. Estes resultados demonstram que o efeito de ambiente é mais importante na definição da performance agronômica da cultura quando se utilizam práticas de manejo que estimulem a obtenção de altos tetos de rendimento.

Fazendo-se uma comparação entre as variações da temperatura e radiação incidente ocorridas nos dois locais (Tabela 3), pode-se verificar que a disponibilidade de radiação solar por superfície foi mai- or na Depressão Central do que no Planalto Catarinense, tanto na fase vegetativa da cultura, concentrada entre outubro e dezembro, quanto na reprodutiva, ocorrida em janeiro e fevereiro. O número de unidades térmicas acumuladas por dia, considerando a temperatura base de $10^{\circ} \mathrm{C}$, também foi maior na Depressão Central do que no Planalto Catarinense. Isto ocorreu em função da maior temperatura atmosférica que caracteriza regiões localizadas em altitudes próximas do nível do mar, quando comparadas com locais mais altos situados na mesma faixa de latitude (18). Por outro lado, a relação entre radiação disponível e tempo térmico durante o ciclo da cultura foi mais alta em Lages do que em Eldorado do Sul nos períodos mais quentes do ano. A maior diferença percentual registrada entre os dois ambientes ocorreu no mês de janeiro, no qual a relação radiação/unidade térmica de desenvolvimento foi $16,5 \%$ mais alta no Planalto Catarinense do que na Depressão Central do Rio Grande do Sul.

Associando-se as variações de temperatura e radiação solar com o comportamento do rendimento de grãos registrado em S4 e S5, pode-se inferir que os maiores tetos de rendimento obtidos em Lages decorreram das menores temperaturas atmosféricas e da maior relação entre radiação disponível por unidade térmica de desenvolvimento. Temperaturas mais baixas verificadas principalmente à noite reduzem a atividade respiratória da planta, aumentando com isto a eficiência de conversão da radiação solar em carbono orgânico e de partição deste carbono para os grãos (24). A redução dos custos metabólicos para a manutenção da planta traduziu-se em maior rendimento de grãos e índice de colheita (Tabela 2).

TABELA3 - Radiação total incidente, soma térmica, radiação incidente por unidade de tempo térmico para a floração, em dois ambientes contrastantes, 2000/2001.

\begin{tabular}{|c|c|c|c|c|c|c|}
\hline \multirow[t]{2}{*}{ Período do ano } & \multicolumn{2}{|c|}{$\begin{array}{l}\text { Radiação Solar } \\
\left(\text { cal } \mathrm{cm}^{-2} \mathrm{dia}^{-1}\right)\end{array}$} & \multicolumn{2}{|c|}{$\begin{array}{l}\text { Soma térmica } \\
\left({ }^{\circ} \mathrm{C} \text { dia }^{-1}\right)\end{array}$} & \multicolumn{2}{|c|}{$\begin{array}{c}\text { Radiação solar } \\
\text { unidade de tempo }\end{array}$} \\
\hline & $\begin{array}{l}\text { Eldorado do } \\
\text { Sul }^{1}-\text { RS }\end{array}$ & $\begin{array}{l}\text { Lages }^{2}- \\
\text { SC }\end{array}$ & $\begin{array}{l}\text { Eldorado do } \\
\text { Sul-RS }\end{array}$ & Lages-SC & $\begin{array}{l}\text { Eldorado do } \\
\text { Sul-RS }\end{array}$ & Lages-SC \\
\hline Outubro/00 & 385 & 384 & 9,6 & 8,5 & 40,1 & 45,2 \\
\hline Novembro/00 & 473 & 424 & 10,2 & 9,2 & 46,3 & 46,1 \\
\hline Dezembro/00 & 494 & 448 & 12,5 & 11,4 & 39,5 & 39,3 \\
\hline Janeiro/ 01 & 457 & 447 & 13,9 & 11,7 & 32,8 & 38,2 \\
\hline Fevereiro/ 01 & 451 & 397 & 15,0 & 12,7 & 30,0 & 31,2 \\
\hline $\begin{array}{c}\text { Outubro a } \\
\text { Dezembro/00 }\end{array}$ & 450 & 419 & 10,8 & 9,7 & 41,9 & 43,5 \\
\hline $\begin{array}{l}\text { Janeiro a } \\
\text { Fevereiro/01 }\end{array}$ & 454 & 422 & 14,4 & 12,2 & 31,4 & 34,7 \\
\hline $\begin{array}{l}\text { Outubro/00 a } \\
\text { Fevereiro/01 }\end{array}$ & 452 & 421 & 12,6 & 10,9 & 36,6 & 39,1 \\
\hline
\end{tabular}

1'Dados coletados no posto meteorológico da Estação Experimental Agronômica da Universidade Federal do Rio Grande do Sul (UFRGS) em Eldorado do Sul.

2Dados coletados no posto meteorológico da Estação Experimental da Empresa Catarinense de Pesquisa Agropecuária e Extensão Rural do Estado de Santa Catarina (EPAGRI) em Lages. 
Além disto, a ocorrência de temperaturas elevadas, principalmente durante as fases de florescimento e início de enchimento de grãos, acelera as taxas de desenvolvimento das estruturas reprodutivas da planta (1). Isto reduz a produção de fotoassimilados por unidade térmica disponível ao desenvolvimento das espigas, refletindo-se em menor disponibilidade de carboidratos para suportar o enchimento de grãos (5).

No presente estudo, o híbrido P 32R21 utilizado em S4 e S5 atingiu o estádio de espigamento nos dias 26 e 30 de dezembro de 2000, em Eldorado do Sul e Lages, respectivamente. Portanto, a fase de dilatação dos grãos, que compreende as duas primeiras semanas após a fertilização, na qual se define o número final de grãos produzidos por espiga (17), coincidiu com o início do mês de janeiro. As temperaturas atmosféricas médias registradas em Eldorado do Sul e Lages nos primeiros dez dias de 2001 foram de $25^{\circ} \mathrm{C}$ e $22,1^{\circ} \mathrm{C}$. Assim, pode-se inferir que as maiores taxas respiratórias da planta e a menor relação entre radiação/unidade térmica de desenvolvimento limitaram a disponibilidade de carboidratos na Depressão Central. Isto provavelmente favoreceu o aborto de óvulos recém fertilizados, principalmente aqueles localizados no ápice do ráquis, reduzindo o número de grãos por espiga e, consequentemente, o rendimento potencial de S4 e S5 em Eldorado do Sul. No caso do peso de 1000 grãos, os maiores valores foram também obtidos nos sistemas destinados a potencializar o rendimento, não havendo diferenças significativas entre os ambientes quanto a este componente do rendimento.

As maiores produtividades registradas em Lages nos sistemas com alto investimento em mane- jo confirmam as ponderações feitas por outros pesquisadores $(10,11)$ de que as regiões com altitudes variando entre 700 e 1000 metros acima do nível do mar no sul do Brasil são as que apresentam melhores características climáticas para maximizar a eficiência de conversão de $\mathrm{CO}_{2}$ em açúcares e convertê-los em maior produção de grãos por área. Neste sentido, dois pesquisadores (11) classificaram regiões com altitudes inferiores a 300 metros como de baixa aptidão para otimizar o rendimento de grãos do milho. Por outro lado, as altas produtividades obtidas em Eldorado do Sul nos Sistemas 3, 4 e 5 demonstram que na faixa de latitude compreendida entre 27 e $30^{\circ} \mathrm{S}$ é possível alcançar-se excelentes rendimentos de grãos de milho, independentemente de altitude, desde que se invista em práticas adequadas de manejo.

\section{CONCLUSÕES}

1 - O efeito do ambiente é mais importante na definição do rendimento de grãos de milho sob alto nível de manejo.

2 - O potencial de rendimento de grãos do miIho é maior em Lages do que em Eldorado do Sul quando se exerce controle dos fatores de produção através do manejo.

3 - A maior relação entre radiação disponível por unidade térmica de desenvolvimento no início do enchimento de grãos incrementa o rendimento potencial do milho no Planalto Catarinense.

4 - É possível obter-se elevados rendimentos de grãos de milho mesmo em regiões de baixa altitude, desde que a cultura seja manejada adequadamente.

\section{REFERÊNCIAS BIBLIOGRÁFICAS}

1. ANDRADE, F.H.; UHART, S.A.; CIRILO, A. Temperature affects radiation use efficiency in maize. Field Crops Research, Amsterdan, v.32, p.17-25, 1993.

2. ANDRADE, F.H. Analysis of growth and yield of maize, sunflower and soybean grown at Balcare, Argentina. Field Crops Research, Amsterdan, v.41, p.1-12,1995.

3. ARGENTA, G.; SILVA, P.R.F. da; SANGOI, L. Arranjo de plantas em milho: análise do estado-da-arte. Ciência Rural, Santa Maria, v.31, n.5, p.1075-1084, 2001.

4. BARNI, N.A.; BERLATO, M.A.; BERGAMASCHI, H.; RIBOLDI, J. Rendimento máximo do girassol com base na radiação solar e temperatura: II. Produção de fitomassa e rendimento de grãos. Pesquisa Agropecuária Gaúcha, Porto Alegre, v.1, p. 201216, 1995.

5. CANTARERO, M.G.; CIRILO, A.G.; ANDRADE, F.H. Night temperature at silking affects kernel set in maize. Crop Science, Madison, v.39, p.703-710, 1999.

6. EMBRAPA-CENTRO NACIONAL DE PESQUISADE SOLOS. Sistema brasileiro de classificação de solos. Rio de Janeiro: Embrapa, 1999. 412p.

7. EVANS, L.T. Processes, genes, and yield potential. In: BUXTON, D.R.; SHIBLES, R.; FORSBERG, R.A.; ASAY, K.H.; PAULSEN, G.M.; WILSON, R.F. (Ed.) International Crop Science I. Madison: Crop Science Society of America, 1993. p.687-696.

8. EVANS, L.T.; FISCHER, R.A. Yield potential: its definition, measurement, and significance. Crop Science, Madison, v.39, p.15441551, 1999.

9. FANCELLI, A. L. Fisiologia da produção e aspectos básicos de manejo para alto rendimento. In: SANDINI, I.; FANCELLI, A. L. (Ed.). Milho: estratégias de manejo para a região sul. Guarapuava: Fundação Agrária de Pesquisa Agropecuária, 2000. p.103116.

10. FANCELLI, A.L. Ecofisiologia e fenologia do milho. In: REUNIÃO TÉCNICACATARINENSE DE MILHO E FEIJÃO, 3., Chapecó, 2001. Resumos. Porto Alegre: EPAGRI, 2001. p. 23-34.

11. FANCELLI, A.L.; DOURADO, D. Gerenciamento da cultura do milho. Piracicaba, 1999. 2 CD-ROM. 
ARGENTA, G. et al. Potencial de rendimento de grãos...

12. FANCELLI, A. L.; DOURADO NETO, D. Produção de milho. Guaíba: Agropecuária, 2000. 360 p

13. GARDNER, F.P; PEARCE, R.B.; MITHCELL, R.L. Physiology of crop plants. Ames: lowa State University, 1985. 327p.

14. LOOMIS, R.S.; AMTHOR, J.S. Yield potential, plant assimilatory capacity, and metabolic efficiences. Crop Science, Madison, v.39, p.1584-1596, 1999.

15. OMETTO, J.C. Bioclimatologia vegetal. São Paulo: Ceres, 1981. 440p.

16. PROGRAMA MULTIINSTITUCIONAL DE DIFUSÃO DE TECNOLOGIA EM MILHO DO RIO GRANDE DO SUL. Recomendações técnicas para a cultura do milho no estado do Rio Grande do Sul. Porto Alegre: FEPAGRO; EMATER/ RS; FECOAGRO/RS, 1999. 146p. (Boletim Técnico, 6).

17. SALVADOR, R. J.; PEARCE, R. B. Proposed standard system of nomenclature for maize grain filling events and concepts. Maydica, Bergamo, v.40, n.1, p.141-146, 1995.

18. SANGOI, L. Aptidão dos campos de Lages (SC) para produção de milho em diferentes épocas de semeadura. Pesquisa Agropecuária Brasileira, Brasília, v.28, p.51-63, 1993.

19. SANGOI, L. Understanding plant density effects on maize growth and development: an important issue to maximize grain yield. Ciência Rural, Santa Maria, v. 31, p.159-168, 2001.

20. SANGOI, L.; ENDER, M.; GUIDOLIN, A.F.; ALMEIDA, M.L.; KONFLANZ, V.A. Nitrogen fertilization impact on agronomic traits of maize hybrids released at different decades. Pesquisa Agropecuária Brasileira, Brasília, v.36, p.757-764, 2001.

21. SLAFFER, G.A.; OTEGUI, M. Is there a niche for physiology in future genetic improvement of maize yields? In: SLAFFER, G.A.; OTEGUI (Ed.). Physiological bases for maize improvement. New York: Haworth Press, 2000. p.1-14.

22. VEGA, C.R.C.; ANDRADE, F.H.; SADRAS, V.O.; UHART, S.A.; VALENTINUZ, O.R. Seed number as a function of growth. A comparative study in soybean, sunflower and maize. Crop Science, Madison, v.41, p.748-754, 2001

23. WILHELM, E.P.; MULLEN, R.E.; KEELING, P.L.; SINGLETARY, G.W. Heat stress during grain filling in maize: effects on kernel growth and metabolism. Crop Science, Madison, v.39, p.1733-1741, 1999.

Recebido em 20/01/2002 Aceito em 12/05/2004 